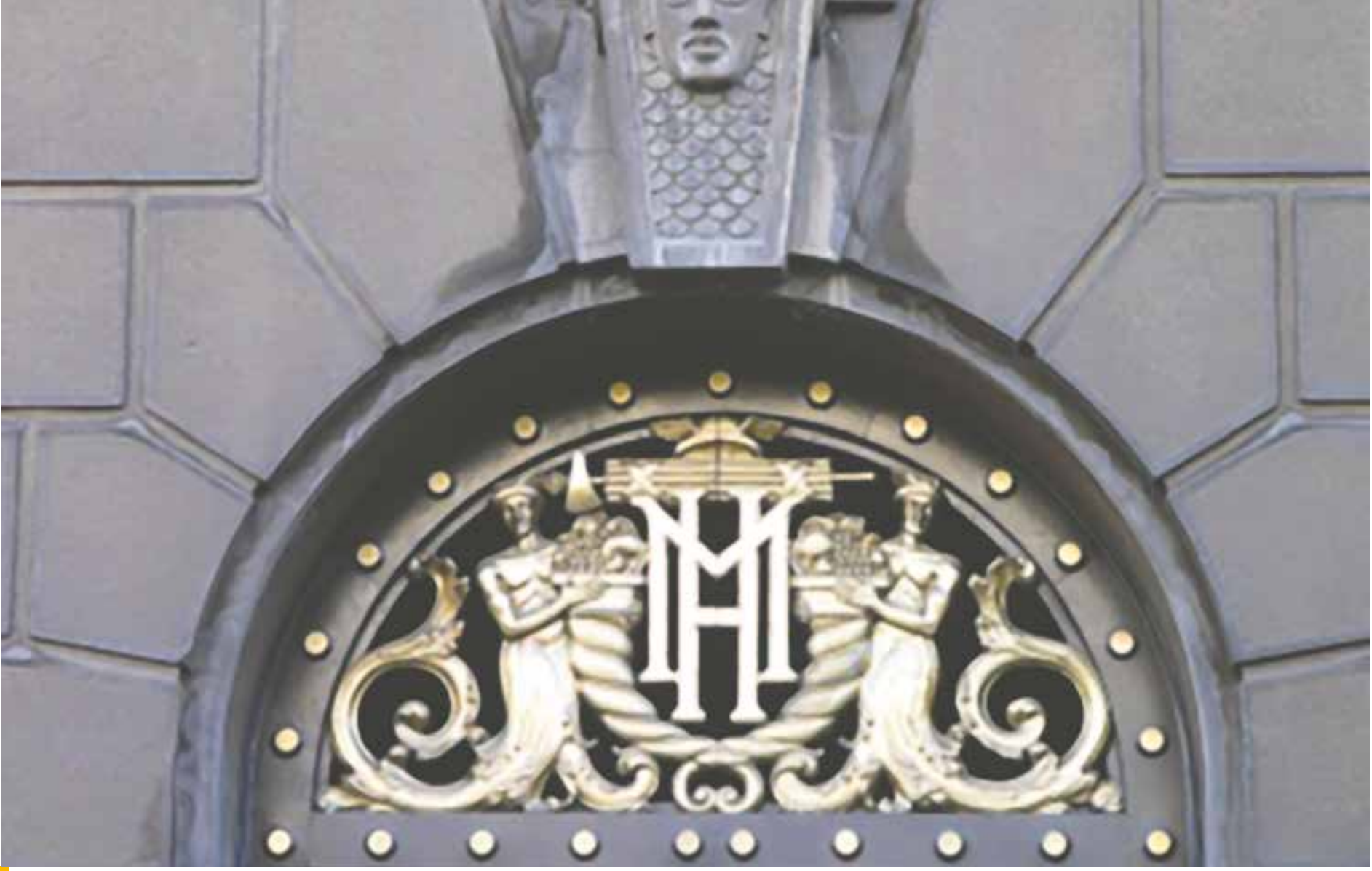

\title{
Presupuesto y déficit fiscal 2019
}
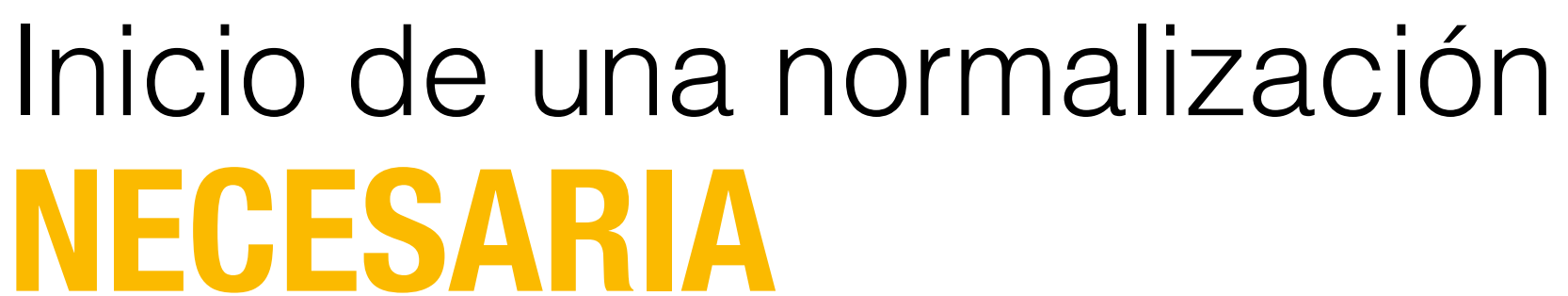

Carlos García, Ph.D. en Economía, University of California (LA), EE.UU, académico FEN-UAH

- Por qué los economistas han inventado este concepto y no usan directamente el déficit fiscal? En efecto, no sería más fácil reducir la discusión económica solo a la diferencia entre gastos e ingresos fiscales. No será un nuevo concepto que los economistas quieren introducir para aguar la fiesta como en el pasado han inventado términos como metas de inflación, asignación de recursos, reducción de costos, asegurar financiamiento, etc. Al final, los economistas son como los aguafiestas de siempre: reduciendo todo a dinero y eternamente haciendo esa preguntilla tendenciosa de cómo se financiará la fiesta. No disfrutarán de la vida estos tipos, o serán unos permanentes amargados.

Bueno, expliquemos en fácil este concepto antes de juzgar tan duramente a los economistas.

En favor de los economistas, tenemos que muchos gobiernos en diferentes países han tendido a hacer fiestas sin pagarlas. Primero, se endeudan, sí con deuda pública, y luego cuando los gobiernos tienen problemas, en la mayoría de los casos debe acabar abruptamente con las fiestas para pagar la deuda o simplemente no pagarla y declararse en quiebra (caer en default otro término inventado por los economistas). Trabajar después de la resaca de una gran fiesta es duro, sin duda.

¿Entonces cómo regulamos que los gastos excedan a los ingresos? Una idea es que los gastos sean siempre iguales a los ingresos fiscales suceda lo que suceda. Sin embargo, no es una buena idea, aunque a primera vista pareciera. Piense en usted mismo, si sus ingresos este año cayeran a la mitad, entonces sacaría a sus hijas y/o hijos del colegio y los volvería a matricular el próximo año. Es probable que hiciese algo diferente, reorganizaría sus gastos y/o buscaría obtener un préstamo. Tampoco, cortaría los seguros de salud y trataría hasta donde pueda pagar la AFP. En efecto, gastar lo que se gana es un buen lema, pero no muy razonable. Para el gobierno, esta regla es incluso más complicada porque existen muchas familias que dependen de los subsidios del gobierno, y como ya no vivimos en la edad medieval, existe un Estado que debe preocuparse por todos nosotros, bueno en la medida de lo posible.

Aquí surge el concepto del balance estructural. Eso sí, pediré un pequeño esfuerzo para imaginarse esta situación. Supongamos (otra palabra muy usada por los economistas) que fijamos nuestros gastos no en función de nuestros ingresos corrientes, sino en los que esperamos ganar. Si pudiéramos determinar con precisión y objetividad, entonces podríamos 
proponer que nuestros gastos fueran iguales a nuestros ingresos esperados. Eso aseguraría que pudiéramos financiar normalmente nuestros gastos claves y no sacrificarlos por caídas temporales en los ingresos.

Por tanto, ¿el balance estructural debe ser cero?, ¿es cero un número "mágico" como lo es la meta de inflación de 3\% para el Banco Central? Es decir, nuestros gastos deben ser exactamente iguales a nuestros ingresos permanentes. Si no existiera incertidumbre, la respuesta es positiva: debe ser cero. Eso sí debemos estar seguros de que los mercados financieros funcionen adecuadamente para que nuestros ahorros compensen las necesidades de fondos en los años que los ingresos corrientes son bajos. En caso contrario, debiera ser positiva, de tal forma que el gobierno acumulara ahorros para aquellos episodios extremos e imprevistos como la crisis financiera del 2008. Puesto, que el caso real es segundo, el balance estructural debe ser positivo. Por tanto, usted debiera tener al menos dos números mágicos en su cabeza, inflación cercana al $3 \%$ y un balance estructural positivo. En otras palabras, una inflación muy por sobre el $3 \%$ (por ejemplo $6 \%$ ) y un balance estructural negativo $(5 \%)$ es sospechoso. Debe considerar estas reglas como las luces que indican en su automóvil que falta agua 0 aceite, en ambos casos, si sigue manejando con esas alarmas prendidas puede ser mortal para su automóvil.

Otro indicador es si su auto anda a una velocidad apropiada, en términos económicos como crece la economía año tras año. Para disfrutar de su auto, a usted le gustaría que anduviera a una buena velocidad. Claro $10 \mathrm{Km} / \mathrm{h}$ es muy poco y $60 \mathrm{~km} / \mathrm{h}$, no es posible por la nueva ley de tránsito, a usted le gustaría andar a $50 \mathrm{~km} / \mathrm{h}$ ni más ni menos. Los economistas han calculado que la economía puede crecer cerca de un $3 \%$ y algo más, esa es la velocidad de nuestro automóvil Ilamado Chile. Este es el tercer número, crecer por ahora al $3 \%$ (los economistas para enredar las cosas le llaman a esto PIB potencial).

Debe reconocerse a estas alturas del artículo, y espero que sigan leyéndolo, que estas tres medidas son muy directas, y aunque cueste reconocerlo, son gracias a los economistas, esos tipos (as) pesimistas y aguafiestas. Usted sabe bien cómo reconocerlos (as),

aparecen en los programas de TV con cara de póker indicando lo que se debiera hacer, como si ellos(as) nunca hicieran algún desarreglo. Pero, se debe reconocer, después de todas estas explicaciones que son útiles, al momento de evaluar cómo va nuestra economía, cual médico ve una radiografía.

Sigamos, en 2017, la inflación fue 2,2\% (¡bien!), el crecimiento del PIB (1,5\%, ¡mal!) y el balance estructural de $-2 \%$ (negativo, ¡mal nuevamente!). Una sola luz verde y dos rojas, preocupante por decir lo menos.

Analicemos la luz roja del balance estructural del 2017 de $-2 \%$. Entre el 2004-2008, el balance estructural no solo fue positivo, sino súper positivo, llegó a un récord de... ¡ $8 \%$ del PIB! Hasta ese año, esta cifra parecía excesiva, y muchos acusaron a los economistas de ser

\section{"Como conclusión, y} tomando seriamente mi rol de economista, el debilitamiento fiscal mostró grietas en el modelo de crecimiento de Chile"

muy ahorradores, además de aburridos. Eso sí, el balance estructural cumplía con la regla de ser positivo, el problema es que 8 puntos del PIB era inusual, en especial para los estándares Latinoamericanos. Solo el 2008, quedó claro que esos ahorros eran necesarios para enfrentar la crisis financiera internacional. Los ahorros se usaron para sostener el gasto del gobierno y con ello la propia economía, que cayó solo un $1 \%$ en 2009 , y se recuperó luego fuertemente hasta el 2013. De ahí en adelante comenzaron los problemas.

A fines de 2013, se esperaba un crecimiento promedio de 4,5\% para el 2014, y fue de 1,9\%. A fines de 2014, se esperaba un crecimiento de $3,0 \%$, para el 2015 fue de $2,3 \%$. A fines de 2015 , se esperaba un crecimiento de 2,5\%, para el 2016 fue de 1,2\%, etc. Creíamos tener un automóvil deportivo y nuevo, en cambio fue uno usado y lento, moviéndose, pero con dificultades cada año. En consecuencia, buena parte de los ingresos, no solo privados sino también del gobierno (recordemos que buena parte son impuestos y por tanto dependen de los ingresos privados), estuvieron bajo lo esperado. El consumo del gobierno, mientras tanto, creció fuerte $3,8 \%, 4,8 \%, 6,3 \%$ y $4 \%$, desde el 2014 hasta el 2017 respectivamente. En resumen, el balance estructural empezó a flaquear para terminar con un $-2 \%$ el 2017 , y notablemente, sin que la economía chilena enfrentara recesión alguna.

En definitiva, una mezcla de proyecciones erradas, presiones por mayor gasto y exceso de optimismo se confabularon para debilitar la posición fiscal. Por supuesto ningún tipo de fiesta irresponsable, pero con un resultado ingrato: la deuda bruta del gobierno pasó de $3,9 \%$ del PIB en 2007 a 23,7\% del PIB en 2017. Si bien es una cifra moderada a nivel internacional, Chile en 10 años acabó con su ventaja, por ejemplo, sobre los países emergentes pertenecientes a la OECD.

El presupuesto del gobierno para el 2019 reconoció que la situación fiscal se deterioró. Así, se comprometió a reducir el déficit estructural en 0,2 puntos del PIB cada año hasta el 2022, con un balance estructural para el 2019 de $-1,6 \%$ llegando a $-1,0 \%$ el 2022. Estas cifras indican lo difícil que será volver a un déficit estructural positivo: casi 10 años a este ritmo desde 2017, sin considerar la posibilidad que pueda ocurrir una crisis internacional. La situación, es compleja, es términos muy coloquiales, se puede echar a perder la estufa, la tostadora de pan y la cocina el 2019, pero no el refrigerador, el cálifont y el automóvil, ahí estaremos en problemas nuevamente. En otras palabras, no debe caer el precio del cobre, ni el mundo crecer menos de lo esperado y/o las expectativas de los empresarios y consumidores decaer.

Como conclusión, y tomando seriamente mi rol de economista, el debilitamiento fiscal mostró grietas en el modelo de crecimiento de Chile. La idea novel de una regla fiscal para estabilizar el gasto y con ello el crecimiento, quedó trasquilada estos años. Si bien, se están tomando medidas correctivas para revivir la regla fiscal, nuevamente quedarán algunas reformas postergadas 0 a medio camino por falta de financiamiento, $y$ con esto, postergamos alcanzar los niveles de desarrollo esperados hace algunos años. $\mathbf{E}$ 